\title{
frontiers
}

FOR YOUNG MINDS

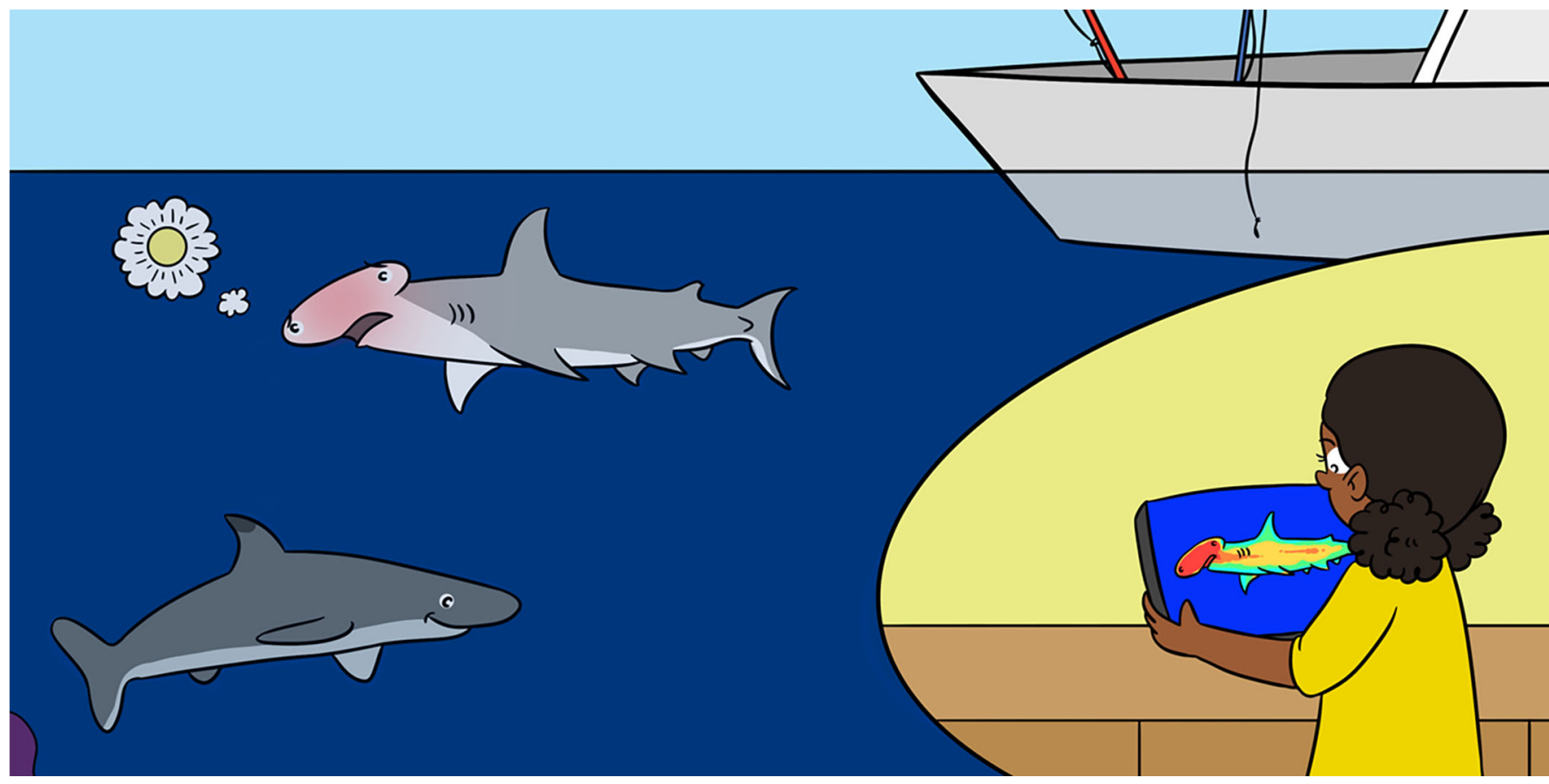

\section{EXPOSURE TO SUNLIGHT AFFECTS THE BODY TEMPERATURES OF SHARKS}

\section{Natascha Wosnick ${ }^{1 *}$, Emygdio L. A. Monteiro-Filho ${ }^{1}$ and Neil Hammerschlag ${ }^{2}$ \\ ${ }^{1}$ Programa de Pós-Graduação em Zoologia, Universidade Federal do Paraná, Curitiba, Brazil \\ ${ }^{2}$ The Rosenstiel School of Marine and Atmospheric Science, University of Miami, Coral Gables, FL, United States}

YOUNG REVIEWER:

LUANA

AGE: 15
Did you know that sharks are sometimes exposed to situations that can hurt them? Because they are big and fierce, sharks are often sought after in fishing tournaments. During capture, sharks are often removed from the water and exposed to the sun. Since shark health is linked closely to their body temperatures, we wondered if this exposure to the sun would affect them. To test this idea, we used a special camera that can record the heat coming off the shark's body surface. We discovered that some shark species are more sensitive to sun, warming up quicker than others. Surprisingly, we also found that warming patterns differed across the body for different species. This study is important because it helps us understand how fishing can affect sharks in different ways, even if the sharks are released back into the water alive. 


\section{TOP PREDATORS}

Animals with few to no predators of their own, residing at the top of their food chain.

THERMAL IMAGING CAMERA

Special equipment that allows the heat released by an animal to be seen using colors.

TAG

Personal identification that an animal receives so that it can be identified later. Tags may consist of a long piece of plastic tubing, a disc, or small coded wire. They contain an identification number that is unique to each animal, as well as contact information from the research team or organization responsible for the study. They can be secured at the shark dorsal fin with a plastic or stainless-steel dart or may be inserted under the skin entirely.

\section{SAFETY RULES-ALWAYS LEAVE A SHARK UNDERWATER}

While marine mammals, such as whales, seals, and dolphins can keep their bodies warm even in cold waters, most sharks cannot do this. Sharks' body temperatures are usually the same as the surrounding water. In fact, the temperature of the surrounding water affects a shark's daily activities, like swimming and hunting [1]. The warmer the water, the more active sharks tend to be.

Sadly, many sharks are killed for their meat and fins, which has resulted in many species becoming threatened with extinction [2]. In many places, people also fish for sharks as sport. Sharks are often targeted for sport fishing since they are big and fierce. Sharks that are captured for sport are often released back into the ocean. Returning them to the sea is very important because big sharks are top predators and help to maintain a healthy balance in the ocean ecosystem. Unfortunately, some sharks that are released back into the water alive may die a few hours later, either because of the stress of capture or because of what happened to them before they were released. When they are caught by fishermen, sharks can get stressed out from experiencing fast changes in the surrounding water temperature. Sharks are often swimming in deep, cold waters when they are hooked, but then they are quickly brought to the surface by the fishing line, where they are exposed to warmer waters that have been heated by the sun [3]. Also, sharks are often removed from the water and exposed to the sun before being released back into the ocean.

Since shark health is closely related to body temperature, we wondered if sun exposure would increase a shark's body temperature. To test this idea, we studied how the body temperature of sharks changes when they are taken out of the water and exposed to the sun for a few minutes. We wanted to find out whether sharks heat up very quickly. We were also curious whether different shark species would be impacted in different ways, and whether some parts of a shark's body would heat up faster or to a higher temperature than other parts. To answer these questions, we took photos of sharks with a thermal imaging camera, which is a special camera that can photograph and measure the heat coming off the bodies of sharks or other animals.

\section{STUDYING SHARKS}

We joined a team of scientists in Florida (United States) who are studying the movements and health of sharks. These scientists need to capture the sharks to measure and tag them before releasing them back into the water. It was at this time that we filmed and photographed the sharks with the thermal imaging camera (Figure 1). Each shark was photographed as soon as it was taken out of the 
Figure 1

A female blacktip shark being thermographed by our team. You can see the hose in the shark's mouth, which is providing fresh ocean water to its gills.

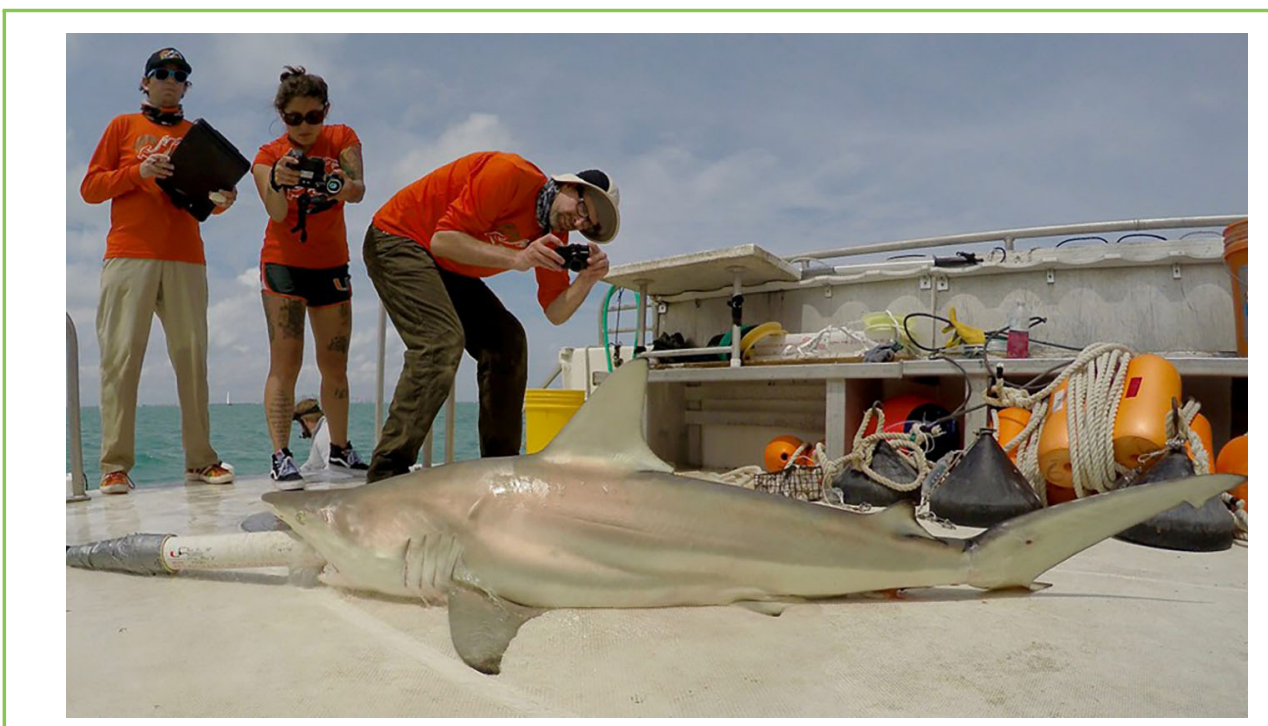

Figure 1

water, and then again right before it was released back into the water. To help the sharks breathe while out of the water, a hose connected to a water pump was placed inside their mouths, which pumped fresh ocean water through their gills. We also measured water and air temperatures and compared those values to the body temperatures of the sharks.

\section{WE DISCOVERED VERY INTERESTING THINGS ABOUT THE SHARKS THAT WE STUDIED!}

We photographed 62 sharks with the thermal imaging camera, including males, females, adults, and juvenile sharks. The smallest shark was a female blacktip shark, measuring $105.5 \mathrm{~cm}$, and the largest was a male great hammerhead shark, measuring $340 \mathrm{~cm}$. Water temperatures were between 20 and $32^{\circ} \mathrm{C}$ and air temperatures between 21 and $34^{\circ} \mathrm{C}$.

We studied 10 different shark species and discovered some very interesting things! Blacktip sharks heated up the fastest, and also heated up pretty evenly along their bodies. The heads of hammerhead sharks warmed faster than the rest of their bodies. For nurse sharks, the sides of their bodies were warmer than the rest of their bodies. At the time of capture, the heads of bull sharks were warmer than the rest of their bodies. However, for both nurse and bull sharks, their temperatures as a whole did not change much while they were out of the water. Finally, we also found that, for most species (lemon shark, dusky shark, sandbar shark, blacknose shark, and tiger shark), the smaller the shark, the warmer the body temperature when exposed to sunlight (Figure 2). 
Figure 2

The shark species we studied, as seen with and without a thermal camera. The temperature scale, shown on the right of each image, is in ${ }^{\circ} \mathrm{C}$. You can see that sharks are warming up in different ways by the color changes showed by the camera.

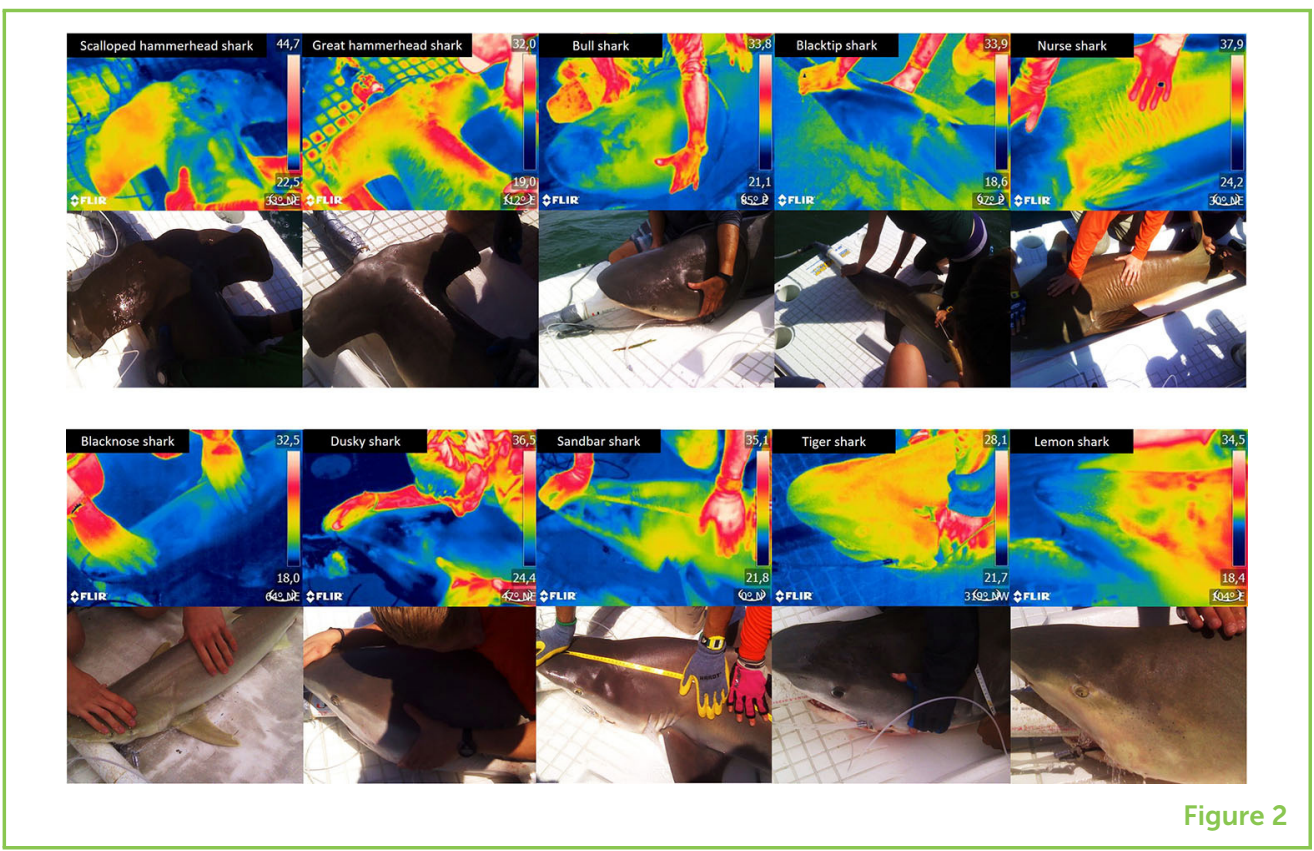

\section{NOW WE KNOW THAT THE SUN AFFECTS SHARKS, BUT WHY IS THIS IMPORTANT?}

Our study revealed that exposure to the sun when they are caught by fisherman can alter the body temperatures of sharks. This could end up affecting sharks' health and survival, even if they are released back into the water alive. Surprisingly, we also found that warming patterns differed across the sharks' bodies for different species. In blacktip sharks, the whole body warmed up faster and more evenly, showing that all parts of the body are sensitive to sun. Other studies show that blacktips are very sensitive to changes in temperature, and that they even change where they are living if the water temperature rises too much [4]. Unfortunately, blacktips are the shark species most fished for sport in the United States.

The highest temperatures that we measured were on the heads of hammerhead sharks, which increased $7^{\circ} \mathrm{C}$ in $<5 \mathrm{~min}$ ! As their heads are very long and very thin, heating happens faster than for other sharks and is possibly more dangerous. Heating of the head is not good, because overheating of the brain can cause a lot of damage. Hammerheads are known to be very sensitive to capture, often dying quickly when caught [5]. So, this species is not a good candidate for catch-and-release fishing and should be released immediately without being removed from the water, to help the sharks survive.

In contrast to other shark species, nurse sharks were warmer on the sides of their bodies right after capture. Since the thermal camera can detect heat released by the muscles after exercise, we believe that the heat we measured on the sides of nurse sharks was related to the activity of their muscles. Nurse sharks struggle a lot on the fishing 
CRANIAL

ENDOTHERMY

Ability to keep the head temperature constant, keeping the brain and eyes protected from sudden changes in the surrounding temperature. line, rolling several times in the same way that crocodiles do. This is very interesting, because most sharks cannot produce enough heat from their muscles to warm their bodies. Our study suggests that nurse sharks may have this ability.

Unlike the heads of hammerheads that heated up in the sun, the heads of bull sharks were already warmer than the rest of their bodies at the time of capture. The ability of an animal to regulate the temperature of its head is called cranial endothermy. Cranial endothermy occurs in some fish, such as manta rays and billfishes. This can be very good for predators, such as bull sharks that hunt in freshwater where it is difficult to see, because warmer brains and warmer eyes allow an animal to think better and see better, helping it to find its prey in darker environments.

All the other sharks studied reacted to the sun in the same way: the smaller the shark, the more it heated up. This is a problem when it comes to fishing, since young sharks are more fragile than adults.

Last but not least, by using math, we calculated what would happen if sharks were exposed to the sun for longer times, like hours [6]. We found that the longer the shark is out of the water, the higher its body temperature will be. This could be problematic for a shark's health if it is kept at the surface or even taken out of the water for a long period during fishing. Also, scientists expect that the ocean's temperature will increase because of climate change. This will affect shark species living near the surface, since surface waters will be warmed more quickly by the sun. Marine biologists expect that, as a result of climate change and rising water temperatures, some shark species will seek out new places to live, while other species may develop skin or eye problems.

Our discoveries show how important it is to use new technologies like the thermal imaging camera to study animals, as we can learn many fascinating things with just one click! Sharks may look big and fierce, but they face many challenges. So, studies like this one are important to help us understand how sharks will respond to fishing and climate change, and what humans can do to help conserve them.

\section{ACKNOWLEDGMENTS}

We thank the University of Miami Shark Research and Conservation Program for research support. We also would like to thank the young reviewer and his mentor Ester Dias for their extremely valuable comments and great interest in our study. Finally, we would like to thank the editor Pedro Morais for his outstanding guidance during the review, making our study more suitable for young audiences. 


\section{ORIGINAL SOURCE ARTICLE}

Wosnick, N., Niella, Y. V., Navas, C. A., Monteiro-Filho, E. L., Freire, C. A., and Hammerschlag, N. 2019. Multispecies thermal dynamics of air-exposed ectothermic sharks and its implications for fisheries conservation. J. Exp. Mar. Biol. Ecol. 51:1-9. doi: 10.1016/j.jembe.20 19.01.002

\section{REFERENCES}

1. Bernal, D., Carlson, J. K., Goldman, K. J., and Lowe, C. G. 2012. Energetics, Metabolism, and Endothermy in Sharks and Rays. Biology of Sharks and Their Relatives. 2nd Edn. Boca Raton, FL: CRC Press.

2. Shiffman, D. S., and Hammerschlag, N. 2016. Shark conservation and management policy: a review and primer for non-specialists. Anim. Conserv. 19:401-12. doi: 10.1111/acv.12265

3. Wosnick, N., Niella, Y. V., Navas, C. A., Monteiro-Filho, E. L., Freire, C. A., and Hammerschlag, N. 2019. Multispecies thermal dynamics of air-exposed ectothermic sharks and its implications for fisheries conservation. J. Exp. Mar. Biol. Ecol. 51:1-9. doi: 10.1016/j.jembe.2019.01.002

4. Kajiura, S. M., and Tellman, S. L. 2016. Quantification of massive seasonal aggregations of blacktip sharks (Carcharhinus limbatus) in Southeast Florida. PLOS ONE. 11:e0150911. doi: 10.1371/journal.pone.0150911

5. Gallagher, A. J., Hammerschlag, N., Shiffman, D. S., and Giery, S. T. 2014. Evolved for extinction: the cost and conservation implications of specialization in hammerhead sharks. Bioscience 64:619-24. doi: 10.1093/biosci/biu071

6. Wosnick, N., Navas, C. A., Niella, Y. V., Monteiro-Filho, E. L., Freire, C. A., and Hammerschlag, N. 2018. Thermal imaging reveals changes in body surface temperatures of blacktip sharks (Carcharhinus limbatus) during air exposure. Physiol. Biochem. Zool. 91:1005-12. doi: 10.1086/699484

SUBMITTED: 09 January 2020; ACCEPTED: 07 August 2020; PUBLISHED ONLINE: 18 September 2020.

EDITED BY: Pedro Morais, University of Algarve, Portugal

CITATION: Wosnick N, Monteiro-Filho ELA and Hammerschlag N (2020) Exposure to Sunlight Affects the Body Temperatures of Sharks. Front. Young Minds 8:126. doi: 10.3389/frym.2020.00126

CONFLICT OF INTEREST: The authors declare that the research was conducted in the absence of any commercial or financial relationships that could be construed as a potential conflict of interest.

COPYRIGHT () 2020 Wosnick, Monteiro-Filho and Hammerschlag. This is an open-access article distributed under the terms of the Creative Commons Attribution License (CC BY). The use, distribution or reproduction in other forums is permitted, provided the original author(s) and the copyright owner(s) are credited 

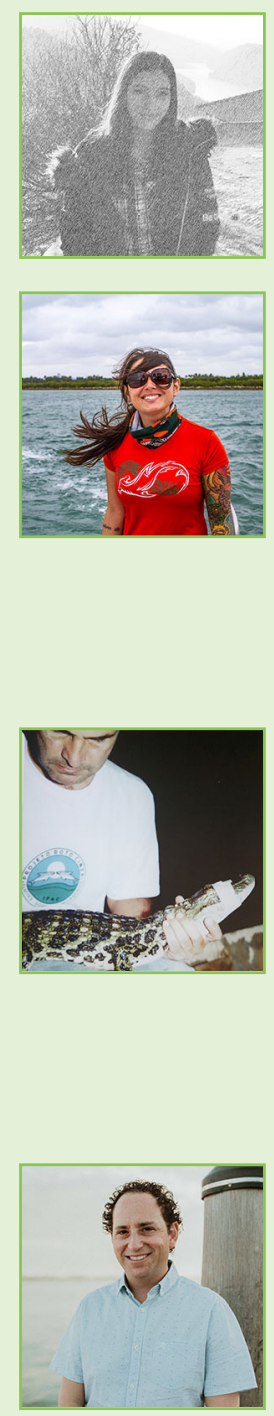

and that the original publication in this journal is cited, in accordance with accepted academic practice. No use, distribution or reproduction is permitted which does not comply with these terms.

\section{YOUNG REVIEWER}

\section{LUANA, AGE: 15}

I like to roller skating, ride a bike, watch movies, and hang out with my friends.

\section{AUTHORS}

\section{NATASCHA WOSNICK}

I am a Brazilian researcher passionate about sharks and rays. My country it is one of the most biodiverse places in the world, but unfortunately overfishing and environmental destruction are harming sharks and rays that live here. For this reason, my research aims to use a set of methodologies to help discover important things for their conservation. Also, I am very interested in marine policy, so I always try to focus my research on species that need better and more efficient protection laws. *n.wosnick@gmail.com

\section{EMYGDIO L. A. MONTEIRO-FILHO}

I am an ecologist who works with marine and terrestrial animals. I am passionate about natural history and use cutting-edge methodologies to study animals in their natural environment. My research aims to understand how the environment and human actions affect the behavior and distribution of several species that lack conservation measures. I also coordinates an important rehabilitation center for marine wildlife in southeastern Brazil, rescuing, taking care and then returning animals that were sick or injured by human activities to nature.

\section{NEIL HAMMERSCHLAG}

I am a marine ecologist at the University of Miami (UM) and the Director of UM's Shark Research \& Conservation Program. For my research, I am studying how human threats to the oceans, such as climate change and overfishing, impact the behavior, health, and survival of sharks. I currently have projects underway in Florida, Bahamas, South Africa, and the Galapagos Islands. I love hockey and am a die-hard Pearl Jam fan, and I have seen them in concert over 40 times and counting. My favorite color is orange. 